\title{
Use of Male Condoms among Adolescents with Free Access at Emergency Contraception-Study among Students from the Public Education System of the Sao Paulo, Brazil
}

\author{
Regina Figueiredo ${ }^{1}$, Neuber José Segri² \\ ${ }^{1}$ Institute of Health of the Department of Health of São Paulo, São Paulo, Brazil \\ ${ }^{2}$ Department of Statistics-Federal University of Mato Grosso (UFMT), Cuiabá, Brazil \\ Email: reginafigueiredo@isaude.sp.gov.br, neuber@usp.br
}

Received 6 January 2014; revised 6 February 2014; accepted 6 March 2014

Copyright (C) 2014 by authors and Scientific Research Publishing Inc.

This work is licensed under the Creative Commons Attribution International License (CC BY). http://creativecommons.org/licenses/by/4.0/

\section{(c) (i) Open Access}

\begin{abstract}
The research conducted in public schools in São Paulo city, Brazil, studied the awareness and use of emergency contraception (EC) and its possible implications on the condoms use. Among the 4929 students, $55.6 \%$ had already had sex, $19.5 \%$ had got pregnant and $7.3 \%$ had had abortions. Condoms were used by $\mathbf{8 8 . 6} \%$ and were options for those who did not have a steady relationship. The EC was used by $\mathbf{3 0 . 3 \%}$ after a faulty condom usage, and by the older ones, with a steady partner. It is needed to be given contraceptive alternatives to reduce the risk and provide access to other contraceptives.
\end{abstract}

\section{Keywords}

AIDS, Adolescents, Hormonal Post-Coital Contraceptives, Emergency Contraception

\section{Introduction}

The AIDS epidemic began in Brazil in the 80s, since then, until June of 2011, reached 608,230 people; and of these 34,218 only in 2010 presented an incidence rate of 17.9 cases per 100,000 inhabitants [1]. Despite having had some stabilization in the number of cases in the 2000s, at the moment, the disease started to spread again, especially among the homosexual men and heterosexual women groups. 
The ratio of cases among men and women fell from 6/1 in 1989 to 1.7/1 in 2010, showing substantial growth of contamination among women; especially adolescents aged 13 to 19 who are infected through sexual transmission. Therefore, the contamination of women results from the exposure to partners with HIV (rate facilitated by the rotation of sexual-affective relationships at adolescent age), being also eased by the presence of other sexually transmitted diseases and the absence of condom usage in all the sexual relations.

In order to reduce the incidence of sexual transmission, the Brazilian government provides about 327 million male condoms a year through the Primary Health Care Services, assigning 37.0\% of the total to the adolescent and the young public [2]. Nevertheless, in 2007, considering the sexually active population aged between 15 and 24, 39.0\% claimed to have had their first sexual intercourse without using a condom, and proportion drops to $35.0 \%$ when considering the last sexual intercourse prior to the survey [2].

Considering only the female adolescents aged between 15 and 19, a national survey conducted in 2006 by the Ministry of Health [3] pointed out that, although the male condom was the most used contraceptive choice at the first intercourse for $80.0 \%$ of them, the usage percentage dropped dramatically to $20.3 \%$ if considering only the 12-month period preceding the survey. The major change in the pattern of condom use, which justifies its abandonment, is the adoption of the contraceptive pill and contraceptive injection, declared regular contraceptive methods used by $79.7 \%$ and $13.5 \%$ of the public in the study respectively [3].

Emergency contraception appears as the second most used method referred by the female group aged 15 to 19 , being used at least once by $10.4 \%$ [3]. This result is very relevant considering that this is a post-coital contraceptive offered in the Brazilian public health services, mostly in situations of sexual violence and that its introduction in the Primary Public Health Units occurred only in 2005 [4]. Thus, great amounts of emergency contraception, even among teenagers, have occurred by direct purchase at drugstores and/or commercial pharmacies, where it is available since 1998 [5]. Such legislation and regulations are available nationally [6] as an important component in order to reduce unplanned pregnancies, and mainly to decrease the high rate of induced abortions in Brazil that are estimated at about 1 million [7], which is considered being a major cause of maternal morbidity and mortality in the country.

The role of the pharmacies and drugstores into the access to the emergency contraception in Brazil is predominant: only in 2007 more than 4 million doses were sold in these commercial chains [8], while only 458,000 (approximately 10\%) were freely distributed through the Public Health Services [9]. Although the prescription is required in order to purchase this contraceptive method, there is no requirement for retaining the document at the time of acquisition in the establishments that sell it. The regulation is not followed in practice, which allows the purchase of the method easily, without prescription [8], as happens with other drugs in the same classification. Due to this situation, recently, the Ministry of Health has announced that it will waive the free distribution of the method, without a prescription, in services related to SUS-Unified Health System.

The behavior of teenagers confronting the free distribution of emergency contraception issue has been the subject of concern for several social groups who fear that the abusive and/or repetitive usage of the method is going to replace the regular use of other contraceptives, including condoms, since the emergency method allows a much more "confortable" post-coital usage [6] [10]. This alarm is usually present in the results of non-probabilistic studies which use convenience samples engaged in the specific health care services designated to this audience [11], and which show rates of $28.0 \%$ in the usage of the method among adolescents and percentages of about $29.0 \%$ in the repeated use. Other studies [12], developed on population-based samples, questioned these data as being overestimated and listed usage percentages of $10.0 \%$ and a percentage of $69.8 \%$ in the permanence of condom use among its users, confirming the acuity of international studies [13]-[15] which indicate that the free distribution of emergency contraception does not promote the abandon or substitution of the regular use contraception, including the condoms and it is being done only as a complementary strategy in unintended risk situations by this population in its day-to-day life.

Considering the limitations of the Brazilian studies and the great misinformation found among the health professionals concerning the emergency contraception and its use, and its benefic use for the reproductive health issues linked to unplanned pregnancy, abortions and maternal deaths reported in several studies and interventions [8] [10] [16], it has to be taken into account the need of representative sample studies concerning the usage profile of the emergency method among adolescents in Brazil, in order to improve the actions of promoting the sexual and reproductive health and prevention of STDs—sexually transmitted diseases, including AIDS, among adolescents. 


\section{Objectives and Methodology}

The research “Emergency Contraception among Public High School Students in São Paulo City”, was developed by the Institute of Health of the Ministry of Health of São Paulo with federal support, aiming to: 1) update the description of sexual practices and prevention concerning pregnancy and STDs/AIDS adopted by adolescents after the regulation and integration of emergency contraception in the public health policies and services; 2) describe the awareness and use of the contraceptive, emphasizing the occasional and repeated use of the emergency contraception; 3) verify the potential links between the emergency contraception use and the consumption of other contraceptives, especially the male condom - the only current choice for STD/AIDS prevention.

For this study we chose to approach the adolescent target group in the public high schools, where the representative age range is between 15 and 19 years. Due to the fact that the institution that proposed the study is located in the health executive body of the State of São Paulo, for this survey, a random sample was defined to characterize the behavioral pattern of 367,323 students from public high schools in the capital of the state of São Paulo, distributed in 476 schools in 2004 [17]. In São Paulo city are enrolled more than 50\% of the state’s high school adolescent students, the greatest target audience of the public health policies for this age group.

The planned sample size was of 6000 students, distributed in 38 schools and four groups per school, drawn at a sample fraction, in each of the four geographical regions of São Paulo (East, North, Central West, and South): $\mathrm{f}=[(a \times M) / 366,471 \times 4 / M i]=5,890 / 366,471=1 / 62.2$, having $a$ and $M$ as the number of randomly selected schools and students in the region $M i$, the number of students enrolled in the school $i$, using the confidence coefficient of $95 \%(z=1.96)$ for carrying out specific crossings between the one-time use of the emergency contraception, as well as the usage in the last six months, approximating a minimum sample size estimated as 5\% between girls and $10 \%$ by boys in relation to their partners, according to a non-probabilistic exploratory study completed previously by one of the authors [12], resulting in a total of 5888 individuals (rounded to $n=6000$ ) of 152 groups (4 groups drawn in each of the selected 38 schools).

Students responded to the semi-structured questionnaire in the classroom, filling out it individually, during the school hours. The self-report instrument approached, mainly: the subject's profile, knowledge and access to information on contraception methods, sexual behavior, contraceptive use, including the one-time use of emergency contraception, in the last six months and at the last intercourse; existence of pregnancies and abortions, and usage of legal and illegal drugs. With respect to responses on the use of the contraception, we adopted the standard questions: "you or your partner with you" so that students of both sexes respond the questions. (n.a.-in the languages where exists feminine and masculine gender).

Data were entered and analyzed using STATA 9 software. Descriptive Statistics, univariate and bivariate percentage distributions, 95\% confidence intervals and chi-square tests with a significance level of 0.05 for rejection of the null hypothesis were performed.

The study conformed to the resolutions on the research ethics in the country, having the approval of the Ethics Committee in Research of the Institute of Health, and was also authorized by the State Department of Education of São Paulo, school directors and informed consent of each of the students involved.

\section{Results}

\subsection{Respondents' Profile}

An amount of 4929 students enrolled in the public high schools in São Paulo responded to the survey. The average age of the students was 16.5 years and the median age was 16 years old. Their distribution with respect to race/color proved to be balanced compared to the profile of the Brazilian population in general (including $46.7 \%$ of blacks and browns). As for religion, a little more than half of the students declared to be Catholics, followed by the group of Evangelicals (23.5\%) (according to Table 1).

An indicator of the socio-economic and cultural status was used as the data on the education level of the head of the household (person designated freely by the respondent), which in $47.9 \%$ of cases had only attended elementary school, $38.2 \%$ up to high school and $13.2 \%$ up to higher education.

Of all the students, 36.9\% CI95\% (32.5; 41.5) reported never having had any classes on sexuality, contraception and condom use in the school.

\subsection{Sexual Practices and the Contraceptive Use}

All respondents declared to have knowledge of at least the male condom as a contraceptive option. Emergency 
Table 1. Profile of students per study period.

\begin{tabular}{|c|c|c|c|c|c|c|}
\hline & & Morning (\%) & Noon (\%) & Evening (\%) & Total (\%) & P-value \\
\hline \multicolumn{7}{|l|}{ Variables } \\
\hline \multicolumn{7}{|l|}{ Gender } \\
\hline & women & 56.3 & 59.3 & 49.8 & 53.4 & \multirow{2}{*}{0.0016} \\
\hline & men & 43.7 & 40.7 & 50.2 & 46.6 & \\
\hline \multicolumn{7}{|l|}{ Age range } \\
\hline & Up to 14 & 6.0 & 14.3 & 0.8 & 3.9 & \multirow{5}{*}{$<0.0001$} \\
\hline & 15 to 16 years & 64.1 & 84.1 & 38.5 & 53.3 & \\
\hline & 17 to 18 years & 27.4 & 1.6 & 48.7 & 36.1 & \\
\hline & 19 to 25 years & 2.4 & 0 & 10.8 & 6.1 & \\
\hline & More then 25 & 0.1 & 0 & 1.2 & 0.6 & \\
\hline \multicolumn{7}{|c|}{ Ethnicity/Race } \\
\hline & Caucasian & 51.9 & 50.0 & 43.3 & 47.9 & \multirow{5}{*}{0.0204} \\
\hline & Afro-American & 9.5 & 8.6 & 11.5 & 10.4 & \\
\hline & Asian & 2.7 & 4.8 & 3.0 & 2.9 & \\
\hline & Latino & 33.7 & 34.9 & 39.2 & 36.3 & \\
\hline & Indigenous & 2.1 & 1.6 & 2.9 & 2.5 & \\
\hline \multicolumn{7}{|l|}{ Religion } \\
\hline & Catholic & 53.9 & 56.8 & 48.5 & 51.4 & \multirow{5}{*}{0.0287} \\
\hline & Evangelical & 21.5 & 25.3 & 25.5 & 23.5 & \\
\hline & Spiritist & 3.7 & 3.2 & 3.2 & 3.5 & \\
\hline & Other & 5.2 & 2.6 & 5.1 & 5.1 & \\
\hline & None & 15.7 & 12.1 & 17.7 & 16.5 & \\
\hline
\end{tabular}

contraception was mentioned spontaneously by 24.3\% CI95\% (22.6; 26.1), and in stimulated questions by 85.4\% CI95\% (83.3; 87.2), (91.8\% of the women and $77.9 \%$ of the men) $(\mathrm{P}<0.0001)$.

Among adolescents, $55.6 \%$ have initiated sexual practices, on average at 15 years of age. From those with this experience, $81.9 \%$ continue to have sex nowadays, $85.9 \%$ using at least once in their life, as a spontaneous response, some prevention contraceptive and 14.1\% having never used any kind of prevention. The most common method was the male condom, followed by the birth control pill and the emergency contraception (see Table 2).

Of the sexually active, $19.5 \%$ had been pregnant at least once. A percent of $81.9 \%$ of these pregnancies were unplanned and for $7.3 \%$ resulted in abortions for the respondent or his partner (5.9\% of the girls above and $2.9 \%$ of the boys interviewed regarding their relations $(\mathrm{P}<0.0001))$.

The study showed that the rate of steady relations is important in the use of prevention contraceptive, as well as the experience of pregnancies $(\mathrm{P}<0.0001)$ and abortions $(\mathrm{P}<0.0001)$, except for the use of condoms mostly practiced by those not involved in steady relationships.

The main reason stated spontaneously for the condom use was its effectiveness in preventing pregnancy (72.3\%) and only as a second purpose, was appointed its use in the STDs/AIDS prevention (63.7\%) (percentages not mutually exclusive).

It was observed that the higher the age, the higher the usage of the birth control pill $(\mathrm{P}<0.0001)$ and the lower the use of the male condoms $(\mathrm{P}<0.0233)$.

\subsection{The Use of Emergency Contraception}

Emergency contraception was used by 30.3\% CI95\% (27.8; 32.9) of the adolescents who already have had sexual intercourse $(37.0 \%$ of the girls and $23.6 \%$ of the boys) $(\mathrm{P}<0.0001)$. This usage shows growth as there is an increase in age $(\mathrm{P}=0.0093)$ and is also higher among those who had regular partner $(76.2 \%)$, than among those 
Table 2. Use of contraceptive methods spontaneously mentioned among students who already have had sex.

\begin{tabular}{|c|c|c|c|}
\hline Variables & & $\begin{array}{l}\text { In life (\%) } \\
\text { CI (95\%) }\end{array}$ & $\begin{array}{c}\text { At the last intercourse (\%) } \\
\text { CI (95\%) }\end{array}$ \\
\hline \multirow{16}{*}{$\begin{array}{c}\text { Spontaneously } \\
\text { Mentioned Method }\end{array}$} & & $\begin{array}{c}85.9 \\
(84.3 ; 87.5)\end{array}$ & $\begin{array}{c}89.2 \\
(87.8 ; 90.3)\end{array}$ \\
\hline & & & \\
\hline & Condom & 67.4 & 67.2 \\
\hline & Condom + Birth Control Pill & 19.1 & 9.0 \\
\hline & Condom + Injection & 1.1 & 0.2 \\
\hline & Condom + Day After Pill & 1.0 & 0.2 \\
\hline & Birth Control Pill & 9.4 & 13.3 \\
\hline & Injection & 1.8 & 1.7 \\
\hline & Female Condom & 0.5 & 0.8 \\
\hline & Coitus Interruptus & 0.4 & 0.7 \\
\hline & DIU & 0.1 & 0 \\
\hline & Adesive & 0 & 0.2 \\
\hline & Female Sterilization & 0.1 & 0.1 \\
\hline & Day After Pill & 0.5 & 0.6 \\
\hline & Other & 0.4 & 0.2 \\
\hline & & $\mathrm{P}<0.0001$ & $\mathrm{P}<0.0001$ \\
\hline
\end{tabular}

who had not $(59.9 \%)(\mathrm{P}<0.0001)^{1}$.

The use of the emergency contraception is also related to the experience of getting pregnant/letting pregnant a partner (50.4\%), almost double than among those who did not pass through this event $(25.6 \%)(\mathrm{P}<0.0001)$. It is noted that in most of the cases, these pregnancies occurred in an unplanned manner.

The most common manner of acquiring the method by adolescents was the direct purchase in pharmacies or drugstores (73.6\%) CI95\% (69.8; 77.0), followed by obtaining it with their sexual partners (21.7\%) CI95\% (18.7; 25.0). Only about $10.7 \%$ acquired it from the health services and/or physicians.

Among respondents, $80.6 \%$ indicated that the emergency contraception is not a regular use method and should be used "sometimes" (39.9\%) or "almost never" or "never" (40.7\%), while its effectiveness for regular use was stated by only $16.9 \%$.

Regarding to the frequency of use and the repeatability among the users of the method during life, $62.4 \%$ CI95\% (57.2; 67.4) used it less than six months prior to the interview $(57.7 \%$ of the adolescent women and $70.1 \%$ of men) $(\mathrm{P}=0.0234)$, with repeated use of $46.2 \%$ within this group of users. Is noted that the use decreases over time and among those who had used it in the six months preceding the survey, less than $10 \%$ did it frequently (almost monthly or more often).

Considering the last intercourse, the main reasons specified for the usage of the emergency contraception was the condom failure, although in the last six months the main declared reason for the practice, was not using condom $(62.2 \%=49.1 \%+12.1 \%)$, see Table 3 .

\subsection{Condom Use X Emergency Contraception}

The male condom was shown as the most used contraceptive method among adolescents, but its use was lower among women $(\mathrm{P}<0.0001)$. The mention of condom use, as shown in Table 4, does not guarantee its frequent and constant use.

The usage of emergency contraception is mostly happening when facing the condom misuse. However, analyzing the behavior in the six months preceding the survey, we note that there is no significant difference in mentioning the condom use among those who made use of emergency contraception and among those who did

\footnotetext{
${ }^{1}$ It is noteworthy that the percentage in men may include the lack of males' knowledge about the contraceptive methods used by theirs partners.
} 
Table 3. Means and motives for use of emergency contraception (EC) among those who have had sex.

\begin{tabular}{|c|c|c|}
\hline Variables & $\%$ & CI (95\%) \\
\hline \multicolumn{3}{|l|}{ Use of EC } \\
\hline In life & 30.3 & $(27.8 ; 32.9)$ \\
\hline In the last 6 months & 17.0 & $(15.2 ; 18.8)$ \\
\hline At the last intercourse & 0.9 & $(0.5 ; 1.4)$ \\
\hline Never & 54.8 & $(52.2 ; 56.0)$ \\
\hline \multicolumn{3}{|l|}{ Use of EC in the last 6 months } \\
\hline 1 time & 56.8 & $(50.5 ; 63.0)$ \\
\hline 1 to 3 times & 33.3 & $(27.4 ; 39.8)$ \\
\hline 4 to 6 times & 3.9 & $(2.1 ; 6.9)$ \\
\hline 6 a 10 vezes & 1.4 & $(0.6 ; 3.7)$ \\
\hline More than 10 times & 4.6 & $(2.6 ; 7.8)$ \\
\hline Total & 100.0 & - \\
\hline \multicolumn{3}{|l|}{ Reason of using EC in the last 6 months } \\
\hline Not using a condom & 49.1 & $(45.4 ; 53.9)$ \\
\hline Coitus interruptus & 12.1 & $(9.2 ; 14.1)$ \\
\hline \multicolumn{3}{|l|}{ Reason of using EC in the last intercourse } \\
\hline Condom break & 38.1 & $(33.2 ; 43.4)$ \\
\hline Did not have a condom at the moment & 23.3 & $(19.4 ; 27.8)$ \\
\hline Condom use refusal & 19.0 & $(15.5 ; 23.1)$ \\
\hline Other & 13.0 & $(10.6 ; 15.8)$ \\
\hline Was under the effect of alcohol/drugs & 3.1 & $(1.7 ; 5.5)$ \\
\hline Was forced to have sex & 0.6 & $(0.1 ; 2.1)$ \\
\hline
\end{tabular}

Table 4. Condom use among those who have had sex by time and frequency.

\begin{tabular}{|c|c|c|c|c|c|}
\hline variables & & $\begin{array}{c}\% \\
\text { Men }\end{array}$ & $\begin{array}{c}\% \\
\text { Women }\end{array}$ & $\begin{array}{c}\% \\
\text { Total }\end{array}$ & P value \\
\hline \multicolumn{6}{|c|}{ Condom use among the sexually active } \\
\hline & In life & 92.7 & 84.3 & 95.4 & $\mathrm{P}<0.0001$ \\
\hline & In the last intercourse & 76.7 & 58.2 & 76.2 & $\mathrm{P}<0.0001$ \\
\hline & Nowadays & 91.8 & 83.3 & 87.8 & $\mathrm{P}<0.0001$ \\
\hline \multicolumn{6}{|c|}{ Frequency of Condom Use Today } \\
\hline & Current usage method & 91.8 & 83.3 & 87.8 & $\mathrm{P}<0.0001$ \\
\hline & "in all the intercourses" & 66.2 & 51.5 & 59.6 & $\mathrm{P}<0.0001$ \\
\hline & "almost all the times" & 24.2 & 27.1 & 25.5 & $\mathrm{P}<0.0001$ \\
\hline & “always” & 9.6 & 21.4 & 14.9 & $\mathrm{P}<0.0001$ \\
\hline
\end{tabular}

not use in that period.

The general use of condoms is significantly higher among those who did not use emergency contraception, especially among those who did use the emergency contraception at the last intercourse (see Table 5).

Although the condom use is estimated as being high, $12.3 \%$ CI95\% $(11.2 ; 13.5)$ of the total amount of respondents explained that they would have sex without a condom even if they were facing a situation of imminent sex. This risky behavior is showed more among men $(70.7 \%)$ than women $(46.8 \%)(\mathrm{P}<0.0001)$, proving that there is a large group of teenagers that are putting themselves in risk, in unforeseen situations, and leave for after the concern on the prevention strategy, according to Table 5 which shows, for example that less than the majority of the teenagers who have ever used the emergency contraception, used a condom in all sexual intercourses. 
Table 5. Condom use among those who had sex by the use of emergency contraception (EC).

\begin{tabular}{|c|c|c|c|c|c|}
\hline & & $\begin{array}{l}\text { Use of EC in life } \\
(\%) \text { CI }(95 \%)\end{array}$ & $\begin{array}{c}\text { Use of EC in the last } \\
6 \mathrm{Months} \\
(\%) \mathrm{CI}(95 \%)\end{array}$ & $\begin{array}{l}\text { Use of EC in the last } \\
\text { intercourse } \\
(\%) \text { CI (95\%) }\end{array}$ & $\begin{array}{l}\text { Never used EC } \\
\text { (\%) CI (95\%) }\end{array}$ \\
\hline \multirow[t]{3}{*}{ Use of Condom } & Yes & $\begin{array}{c}85.0 \\
(81.8 ; 87.8)\end{array}$ & $\begin{array}{c}87.1 \\
(82.4 ; 90.7)\end{array}$ & $\begin{array}{c}63.6 \\
(32.3 ; 86.5)\end{array}$ & $\begin{array}{c}91.7 \\
(89.3 ; 93.2)\end{array}$ \\
\hline & No & $\begin{array}{c}15.0 \\
(12.2 ; 18.2)\end{array}$ & $\begin{array}{c}12.9 \\
(9.3 ; 17.6)\end{array}$ & $\begin{array}{c}36.4 \\
(13.5 ; 67.7)\end{array}$ & $\begin{array}{c}8.3 \\
(6.8 ; 10.2)\end{array}$ \\
\hline & $\begin{array}{l}\text { condom "in all the } \\
\text { sexual intercourses" }\end{array}$ & $\begin{array}{c}40.2 \\
(35.3 ; 45.4)\end{array}$ & $\begin{array}{c}37.9 \\
(31.7 ; 44.5)\end{array}$ & $\begin{array}{c}35.5 \\
(12.5 ; 66.5)\end{array}$ & $\begin{array}{c}67.6 \\
(64.5 ; 70.6)\end{array}$ \\
\hline
\end{tabular}

\section{Discussion}

The research shows that despite having information about the contraceptive methods for all teenagers (especially with respect to the male condom and the birth control pill), a significant percentage of those who have sexual practice never used contraceptive prevention, proving their risk condition to pregnancy and STDs/AIDS. This exposure enhanced by the alternation of partners in relationships/dates/"one night stands" that is currently a characteristic behavior of this age group in Brazil, points out the potential risks become reality when looking at the indexes on pregnancy and abortion.

Among those using contraception, although the male condom is the most frequent method used among adolescents, its use drops with increasing age, when commitment in relationships and the experience of pregnancy and abortion exist, indicating a behavior of preventive "migration" toward the adoption of high efficiency hormonal contraceptive options (such as the birth control pill and the contraceptive injection, the most popular and available in the country), which was also observed by other authors [18].

Emergency contraception has been increasingly used by adolescents, comparing the data collected in earlier studies [19] [20], and has already been used by about one third of the sexually active teens in the city of São Paulo. Confirming other studies [11] [21], the use of this method is not driven by health professionals, but by self-medication and direct acquisition in pharmacies, probably due to the complex access of this audience at Public Family Planning Services and at the contraceptives in the Public Health Services [4], conducting to cases of misuse and even intentional usage (found by Araújo \& Costa [22]).

Confirming international studies [13]-[15] and non-sampling studies conducted in Brazil [19], the research shows that the main reason to use (almost 40\%) emergency contraception has been done for a recommended situation: condom failure. This is contrary, so far, to the exaggerated perspectives of abusive usage by most adolescents.

The remaining (about 60\%) used it for other reasons such as the non-use of contraceptive prevention or protection during the intercourse. Also, there is noticed adoption of emergency contraception after the use of behavioral methods with low contraceptive efficacy (as the calendar-based method and coitus interruptus); this was observed in one third of cases in the research, confirming its need in these risky behavior cases reported by other authors [19].

The use of emergency contraception once was not associated with the abandonment of condoms, in the same way that using the emergency method in the last six months was not associated with the non-use of male condoms among the surveyed male and female adolescents.

The use of the method in order to replace the recommended contraceptive choices for regular use, or in cases of repetitive intended preventive contraceptive absence almost every month, showed a minority (less than 10\% of adolescents who used it), close to the results found in recent studies in the country [23] [24]. It noted that this repeated and/or frequent use of the emergency method (close to or more than 1 dose/month) was reported by older adolescents as it is twice more than the dose for those who already got pregnant and are in sexual intercourse with the regular partner. This indicates that the use of emergency contraception appears to be associated with the same factor that leads to the fall of condoms usage, according to several studies by other authors [25], including among adolescents [26]: the manifestation of sexual-affective committed relationships, as also found in [24]. This behavior affects mainly adolescent women who tend to have partners not necessarily teens, but also the older, having premature "more adult" behaviors detected in most of the population.

The study shows that there is a connection between the non-use of condoms and the use of emergency contraception, implying that the trend of non-use or abandonment of the barrier method when having a steady part- 
ner leads to greater use of emergency contraception; at the same time there is effectively a smaller group that has been taking emergency contraception deliberately and erroneously. From this perspective, there is a need to expand the access of adolescents to information and public services that reinforce the need of condom usage with the regular partners, information and access to the risk reduction strategies, such as being HIV tested and having condom use agreements with third parties [27], in case of wanting to abandon the condom use when having a stable relationship and the adoption of effective regular contraceptive methods for continuous use.

The adolescent population, especially women, according to the study, is exposed not only to situations of infection with STDs, including HIV/AIDS, but to pregnancy due to the diverse unsafe behaviors that they adopt. Among those adopting the repeated use of the emergency contraception, it is more frequent among those who use behavioral methods of low efficacy and among those who have a stable partnership. This risk shows it is continuous and still unsolved for many couples, since it is observed that most of those who had pregnancies and abortions are the share that continues to adopt risky behaviors, constituting a subgroup within the group of adolescents, being most vulnerable in sexual and reproductive health.

Prevention actions in sexual and reproductive health, including the reinforcement of the condom, proper use of emergency contraception and adoption of more effective contraceptive methods, should be carried out systematically in schools, contrary to what is observed in the research, promoting health education that best reaches these adolescents in their day-to-day lives, as few of them attend health services, strengthening intersectional actions directed by the Ministry of Health [6]. Thus, cases of misuse of contraceptives in general could be avoided, as well as several cases of unplanned pregnancy and abortion.

The lack of education only stimulates a generation to grow up uninformedly and increases problems and the percentage of young people mistakenly using emergency contraception to understand it as a continuous postcoital option.

As a strategy to stimulating the reliability on the condom use in all partnerships and relationships, this method should be presented under a more efficient approach, being introduced more as a contraception method and not necessarily being associated with the disease and AIDS, since there exists the concern of pregnancy which is a more current motivation when adopting behaviors inside couples, which was already proved in other studies [28] [29].

It is important to emphasize that at this moment when the information and use of emergency contraception are spreading. It is essential that policies that encourage condom use and prevention strategies for STDs/AIDS among adolescents and young people do not shy away from addressing this issue.

\section{References}

[1] Brazil Ministry of Health (s/d). STDs/AIDS and Viral Hepatitis Department (2012) AIDS in Figures. Accessed in February of 2012. http://www.AIDS.gov.br/pagina/AIDS-no-brasil.

[2] Brazil Ministry of Health (2008) PCAP_Awareness Research, Attitudes and Practices Related to STDs and AIDS of the Brazilian Population. Brasilia: The Ministry of Health Publishing House 2008. Accessed in February of 2012. http://www.AIDS.gov.br/publicacao/pcap-2008

[3] Brazil Ministry of Health (2008) PNDS 2006 - National Survey on the Demography and Health of Women and Children. Brasilia: The Ministry of Health Publishing House.

[4] Figueiredo, R., Bastos, S.H. and Telles, J.L. (2012) Profile on the Free Distribution of Emergency Contraception for Adolescents in São Paulo's Counties. Journal of Human Growth and Development, 22.

[5] Figueiredo, R. (2004). Brazil: IPAS. Journal of Sexual and Reproductive Health. Accessed in February of 2012. http://www.ipas.org.br/arquivos/10anos/Regina_CE2004.doc

[6] Brazil Ministry of Health (2006) Emergency Contraception: Questions and Answers for Health Professionals. Brasilia: Ministry of Health Publishing House.

[7] Monteiro, M.F.G. and Adesse, L. (2006) Estimativas de aborto induzido no Brasil e Grandes Regiões. In: Anais do XV Encontro Nacional de Estudos Populacionais. ABEP, Belo Horizonte. Disponível em. Acessado em março de 2013. http://www.scielo.br/scielo.php?script=sci_nlinks\&ref=000171\&pid=S1413-8123200900040001500031\&lng=en

[8] Bastos, S., Bonfim, J.R.A., Kalckmann, A.S., Figueiredo, R. and Fernandes, M.E.L. (2009) The Prevention of Sexually Transmitted Diseases and the Emergency Contraception Demand in Sao Paulo's Pharmacies and Drugstores. Health and Society Magazine, 18, 787-799.

[9] Brazil Ministry of Health (2011) Contraceptives Acquisition Spreadsheets. Brasilia: MS.

[10] Figueiredo, R. (2002) II Workshop Training for Promoters of Emergency Contraception: Focused on the Adolescent 
Public. Sao Paulo: NEPAIDS/USP. Accessed in February of 2012.

http://nepAIDS.vitis.uspnet.usp.br/wp-content/uploads/2010/04/relat2treinamentoce.pdf .

[11] Monteleoni, M.L., Takiuti, A.D., Conceição, I. and Kerr, J. (2005) Emergency Contraception and the Adolescents. CD Room I Latin American Congress of Gynecology and Obstetrics. Summary. Accessed in June of 2010. http://www.redece.org/resumo20albertina.pdf

[12] Figueiredo, R. and Peres, C. (2002) Research Report. Exploratory Study on the Use of Emergency Contraception for Adolescents. CD Conference Room of the First CLAE Conference-The Right to the Emergency Contraceptive in Latin America and Caribbean. Quito: CLAE. http://www.usp.br/nepAIDS/cam-ce.pdf

[13] Belzer, M., et al. (2003) Advanced Supply of Emergency Contraception for Adolescent Mothers Increased Utilization or without Reducing Condom Contraception Primary Use. Journal of Adolescent Health, 32, 122-123. http://dx.doi.org/10.1016/S1054-139X(02)00613-4

[14] Raine, T., et al. (2005) Direct Access to Emergency Contraception through Pharmacies and Effect on Unintended Pregnancy and STIs-A Randomized Controlled Trial. Journal of the American Medical Association, 293, 54-62. http://dx.doi.org/10.1001/jama.293.1.54

[15] Camp, S.L., Raine, T.R. and Wilkerson, D.S. (2003) The Benefits and Risks of Over-the-Counter Availability of Levonorgestrel Emergency Contraception. Contraception, 69, 309-317. http://dx.doi.org/10.1016/j.contraception.2003.08.011

[16] Alves, V.S., Ludemir, A.B. and Ribeiro, C. (2004) Diagnosis of Emergency Contraception in the Municipal Health Network of Recife Region. Curumim Group, Recife, 34 p.

[17] Ministry of Education of São Paulo State (2004) School Census 2004. State Secretaryof Education of São Paulo, Sao Paulo.

[18] Barbosa, R., et al. (2006) Awareness on STDs/AIDS, Hepatitis and Sexual Behavior of the University Students of Sao Jose do Rio Preto, SP. Brazilian Journal of Sexual Transmitted Diseases, 18, 224-230.

[19] Andalaft Neto, J. (2003) The Sexual Behavior in Adolescence-The Role of Emergency Contraception. Journal of Sogia-Brazil, 6.

[20] Borges, A.L.V., Fujimori, E. and Nichiata, I.Y.I. (2008) The Use of Emergency Contraception among Young University Women Students. Sao Paulo. http://www.abep.nepo.unicamp.br/encontro2008/docsPDF/ABEP2008 1424.pdf

[21] Silva, F.C. (2009) Emergency Contraception: Awareness, Experience and Attitude of Health Care University Students from Four Federal Universities in Brazil. Master Degree Dissertation, Federal University of Sao Paulo, Sao Paulo.

[22] Araujo, S.P. and Costa, L.O.B.F. (2009) Sexual Behavior and Emergency Contraception among Adolescents in Pernambuco Public Schools, Brazil. Journal of Public Health, Rio de Janeiro, 25, 551-562.

[23] Moraes, S.D.T.A., Alanino, S., Amaral, S.F., Segri, N.J., Di Caprio, L.G. and Moraes, E.M. (2009) Use of Emergency Contraception among Medical University Students of Uninove University. First State Seminar on Women's Health, Ministry of Health, 8-10 March 2009, Abstract and Poster.

[24] Lefevre, F., et al. (2010) Adolescent Pregnancy and the Morning-After Pill: Outline on Its Implications among Adolescents and Health Professionals. Partial Research Report, School of Public Health/USP, CNPQ, MS, IPDSC, Sao Paulo.

[25] Paiva, V., Venturi, G., França Jr., I. and Lopes, F. (2004) Condom Use: A National Survey MS/IBOPE, Brazil 2003. IBOPE, Sao Paulo. http://www.midiaindependente.org/pt/blue/2004/03/276094.shtml

[26] Geluda, K., Bosi, M.L.M., Cunha, A. and Trajman, A. (2006) “When One Doesn’t Want to, Two Don’t Argue”: A Study on the Constant Condom Non-Use by the Adolescents in the City of Rio de Janeiro, Brazil. Public Health Journal, 22, 1671-1680. http://www.scielosp.org/scielo.php?pid=S0102-311X2006000800015\&script=sci_abstract\&tlng=e

[27] Yamaçake, A., et al. (2010) Conjugalities and Prevention of STDs/AIDS. CRT DST/AIDS, Sao Paulo, 42 p.

[28] Figueiredo, R. and Peña, M. (2000) Emergency Contraception: A Contraceptive Option in the Time of STDs/AIDS? NEPAIDS/USP, Sao Paulo.

[29] Santos, N. (2002) Women and Their Reproductive Decisions, given the HIV/AIDS Epidemic. PhD Thesis, University of Sao Paulo, São Paulo. 